\title{
Agroindustrialização e arranjos produtivos locais como estratégia de diversificar e fortalecer a agricultura familiar no RS
}

\author{
Agroindustrialization and local productive arrangements as a strategy to diversify and strengthen \\ family agriculture in $R S$
}

\author{
Mirian Fabiane Strate ${ }^{1}$ \\ Marcelo Antônio Conterato ${ }^{2}$
}

\section{Resumo}

A fragilidade no acesso aos mercados monopolizados, por parte dos agricultores familiares, impulsiona a procura por novos processos e práticas que emergem paralelamente aos grandes impérios alimentares. Nesse contexto surgem novos mercados, que coexistem com os circuitos comerciais como as feiras, mercados integrados ao turismo, agroindústrias familiares e os institucionais, criando novos circuitos mercantis. O objetivo deste trabalho foi analisar como os arranjos produtivos locais podem fomentar a diversificação da agricultura familiar, relocalizando a produção de alimentos através das cadeias curtas, estimulando a heterogeneidade e promovendo o desenvolvimento rural. A pesquisa foi realizada a partir do Arranjo Produtivo Agroindústria familiar, estrutura de governança que impulsiona a instalação, regularização e associativismo de agroindústrias no Vale do Taquari, RS. A metodologia utilizada foi a análise documental e entrevistas com gestores do APL Agroindústria e proprietários de agroindústrias integrantes do APL. Como resultado pode-se observar que as políticas públicas de fomento para a implementação e fortalecimento dos APLs e incentivo ao turismo constituem-se estratégias que podem fortalecer a agricultura familiar, promovendo a construção e o acesso a novos mercados, a criação e o desenvolvimento de novos produtos, promovendo a sucessão rural, diversificando as atividades produtivas, gerando renda através de novos arranjos sociais e estruturas de governança horizontalizadas.

Palavras-chave: Agricultura familiar. Cadeias curtas. Agroindústrias. Mercados. Arranjos produtivos.

\begin{abstract}
The fragility of farmers' access to monopolized markets drives the search for new processes and practices that emerge parallel to the great food empires. In this context, new markets emerge, which coexist with the existing commercial circuits, such as fairs, integrated markets for tourism, family agroindustries and institutional ones, creating new market circuits. The objective of this work was to analyze how local productive arrangements can foster diversification of family agriculture, relocating food production through short chains, stimulating heterogeneity and promoting rural development. The research was carried out from APL Agroindústria, governance structure that drives the installation, regularization and associativism of agroindustries in Vale do Taquari, RS; the methodology used was the documentary analysis and interview to APL Agroindústria's managers and APL's agroindustry owners. As a result it can be observed that the Public Policies of foment for the implementation and strengthening of the APLs, and incentive to the tourism, constitute strategies that can strengthen family agriculture, promoting the construction and access to new markets, creating and developing new products, promoting rural succession, diversifying activities productive, generating income, through new social arrangements and horizontal structures of governance. Keywords: Family farming. Short chains. Agroindustries. Markets. Productive arrangements.

\footnotetext{
1 Mestre em Desenvolvimento Rural pela Universidade Federal do Rio Grande do Sul (UFRGS). E-mail: mirianfabiane@gmail.com.

${ }^{2}$ Doutor em Desenvolvimento Rural (UFRGS). E-mail: marcelo.conterato@ufrgs.br.
} 


\section{Introdução}

Alimentos nos conectam com o ambiente, com a economia, com a saúde, além de conectar entre si uma rede de pessoas, da produção ao consumo. Comer é mais que ingerir alimentos; compreende as relações pessoais, sociais, culturais, econômicas e políticas que estão envolvidas no ato de alimentar-se. Se somos o que comemos, temos que nossa identidade se define pelo que comemos, mas também como comemos, onde e com quem comemos (MENASCHE, 2015, p. 4). Para a autora, os saberes e as práticas da alimentação são entendidos como um patrimônio cultural, de grupos sociais específicos inseridos em seu território.

Em um mundo em que cresce a quantidade de alimentos produzidos e processados industrialmente, também aumenta a preocupação com sua origem e a forma como são elaborados. Essas preocupações com a procedência dos alimentos e a confiança neles têm concentrando grande parte das atenções dos estudos rurais atuais. Diversas contribuições analíticas são encontradas na literatura internacional, as quais têm realizado o esforço de explorar as relações entre os sistemas alternativos e convencionais, focando nas trajetórias do desenvolvimento e nos resultados das iniciativas de localização (FONTE, 2008; TREAGER, 2011). O tema da relocalização espacial, assim como da identidade de quem produz, são duas das mais importantes características do processo que vem sendo chamado de quality turn, termo que expressa o papel cada vez mais ativo dos consumidores na construção de qualidade, bem como de propostas alternativas aos mercados homogeneizantes (GOODMAN; DUPUIS; GOODMAN, 2012). Segundo Goodman (2003), os debates em torno dos circuitos curtos de produção e abastecimento também representam uma resposta crítica aos grandes circuitos produtivos e às próprias crises e escândalos alimentares. Um dos aspectos centrais e decisivos na organização das cadeias curtas de suprimento refere-se à redefinição e mesmo a construção das relações com os mercados. Não há cadeia curta sem que ocorra o encurtamento ou estreitamento das distâncias e dos contatos entre agricultores e consumidores. Logo, a análise de como se dá esse processo de construção de mercados passa a ser essencial para a afirmação e fortalecimento das cadeias curtas.

A fragilidade no acesso aos mercados monopolizados, por parte dos agricultores, impulsiona a procura por novas dinâmicas de desenvolvimento. Nesse contexto emergem novos mercados, que coexistem com os circuitos comerciais já existentes, como as feiras, mercados integrados ao turismo, agroindústrias familiares e os institucionais, criando novos circuitos mercantis. Qual o papel dos mercados na construção da autonomia, na manutenção da heterogeneidade e na reprodução social dos agricultores familiares? 
Este artigo aborda a diversificação da agricultura familiar frente à inserção em novos mercados, a partir dos arranjos produtivos locais, instituídos através de políticas públicas, uma estrutura de governança que impulsiona a instalação, regularização e integração de agroindústrias no Vale do Taquari. A pesquisa combinou aspectos quantitativos e qualitativos. O caráter quantitativo é expresso pela mensuração e análise de diversas variáveis, obtidas de fontes primárias e secundárias, combinando a pesquisa bibliográfica, a pesquisa documental e a pesquisa de campo. A pesquisa bibliográfica e documental foi adotada para, a partir de dados quantitativos, caracterizar a região estudada e compreender a dinâmica da agricultura no Vale do Taquari. Os dados foram obtidos através do IBGE, Censo agropecuário de 2006, FEE, Codevat, Amturvales e Codeter, Plano Territorial de Desenvolvimento Rural Sustentável. O caráter qualitativo foi desenvolvido através de entrevistas semiestruturadas e observação participante a proprietários de três agroindústrias integrantes do arranjo produtivo e com os gestores do APL Agroindústria Vale do Taquari.

\section{Práticas de agroindustrialização como estratégia de desenvolvimento rural}

A agroindústria familiar rural é uma forma de organização na qual a família transforma a matéria-prima oriunda da pequena propriedade em saborosos alimentos, visando à geração de renda. Para Long (2001), a heterogeneidade é uma característica estrutural desse processo, estando associada à construção do conhecimento local e, portanto, à produção e reprodução dessa heterogeneidade.

Segundo Mior (2005), a industrialização dos produtos agropecuários realizados pelos agricultores familiares não se constitui em uma atividade recente, pois faz parte da própria história e da cultura desses pequenos produtores. No princípio, os produtos processados eram destinados para o consumo da família e, em menor grau, para as trocas estabelecidas entre os agricultores. Com a reestruturação dos mercados a partir das mudanças nos hábitos de consumo, a agroindustrialização familiar que estava vinculada com uma economia de subsistência passa a se encontrar inserida nos mercados locais, nacionais e internacionais, o que permite acumular e reproduzir recursos dentro da agricultura familiar a partir da comercialização de produtos processados.

Para Maluf (2004) as tendências recentes do sistema agroalimentar caracterizam-se pela coexistência de processos de padronização e de diferenciação no consumo dos alimentos, cujos reflexos vão até a etapa da produção agrícola. De um lado, assiste-se à continuidade da concentração do processamento agroindustrial para fazer frente aos requisitos da produção em grande escala, ainda que as novas tecnologias permitem que a maior escala de produção seja acompanhada da diferenciação dos produtos finais. Uma das consequências dessa tendência tem sido o 
comprometimento da sobrevivência da agricultura familiar nas regiões e nas cadeias produtivas onde ela tem presença tradicional, como demonstra a seleção que as grandes corporações promovem entre os agricultores integrados que lhes fornecem matéria-prima na avicultura, suinocultura e pecuária leiteira. De outro lado, a valorização de produtos com atributos diferenciados de qualidade cria novas oportunidades de mercado, muitas das quais acessíveis aos agricultores de pequeno e médio portes.

Wilkinson (2003) afirma que a condição de ser visto como "pequeno" passa a ser percebida cada vez mais como uma vantagem estratégica na medida em que for associada à tradição, à natureza, ao artesanal e ao local - um conjunto de valores agora premiado pelo mercado consumidor. Assim, a possibilidade de novos padrões de qualidade (associado ao artesanal, ao familiar e a valores ambientais) e a certificação desses valores por selos de garantia passa a ser um excelente instrumento para a construção social dos novos mercados para a agricultura familiar. Nesse cenário ela é obrigada a atender uma série de padrões de produção que pretendem garantir a qualidade dos produtos, ou como expressa Wilkinson (2003, p. 05), ao aludir sobre o resgate da imagem tradicional de "pequeno produtor", "como estratégia de mercado, exige tanto uma reinvenção de tradições como a adoção de práticas novas, a medida em que estas tradições agora tenham como aval um exigente consumidor urbano".

Entre as formas de organização espacial baseadas na proximidade entre agricultores e consumidores encontramos os Sistemas Agroalimentares Localizados (Sial). Eles podem ser definidos como “organizações de produção e de serviços (unidades de produção agrícolas, empresas agroalimentares, comerciais, de serviço) associadas por suas características e seu funcionamento em um território específico" (CIRAD, 1996). Mais do que uma simples forma de organização, o Sial demonstra que a territorialização da produção não se limita à indústria tradicional ou àquela da inovação; ela pode apresentar características próprias, sintetizadas por Pecqueur (2009, p. 85) apud Muchnik (2002)

A função de identidade particular dos bens alimentares: são os únicos a não serem usados, mas incorporados, no sentido próprio, pelos consumidores. A especificidade da matéria-prima viva, perecível, heterogênea e por natureza sazonal. A ligação com as características do meio e a gestão dos recursos naturais. O saber-fazer e as competências mobilizadas, tanto na etapa da produção, quanto nas etapas da transformação e do consumo dos produtos.

Para Pecqueur (2001), a forma Sial pode tomar um rumo muito mais complexo quando os territórios produzem vários bens e serviços, associados ao turismo e ao lugar, um modelo denominado pelo autor como "cesta de bens".

A atividade agroindustrial não se constitui uma novidade para os agricultores familiares, fazendo parte da sua própria história e da sua cultura, e emerge como uma prática alicerçada no seu 
conhecimento histórico, melhorando as suas maneiras de fazer e de produzir, culminando com a agroindustrialização. A busca por alimentos saudáveis e alicerçados na herança cultural, bem como o contato com a natureza e o meio rural de uma sociedade cada vez mais urbana, dá visibilidade aos produtos com atributos diferenciados de qualidade, criando novas oportunidades de mercado, muitas das quais acessíveis aos agricultores familiares.

\section{Agricultura familiar do Vale do Taquari - RS}

A agricultura familiar que emergiu na região do Vale do Taquari, a partir da diversidade de povos e culturas indígenas, imigrantes açorianos, portugueses, alemães e italianos, dedicou-se à policultura e à pecuária de pequena escala, baseada na produção para o autoconsumo, mas vendendo o excedente a comerciantes que atendiam ao mercado de consumo da capital, facilitado pela proximidade geográfica. Conforme Berold et al. (2006), a produção para autoconsumo era composta de carnes bovina, suína e de aves, leite, banha, ovos, farinhas de trigo e milho, raízes comestíveis (mandioca), batata-doce e frutas cítricas, além de algumas leguminosas, como feijões e lentilhas. Inicialmente, dedicaram-se à policultura e à pecuária de pequena escala, sobretudo para atender ao mercado de consumo da capital, o que era facilitado pela proximidade geográfica. Além do "ouro branco" das colônias (banha suína), o rol de artigos era amplo. Segundo Ahlert e Gedoz (2001), entre 1900 e 1916, em Estrela, existiam alambiques, curtumes, cervejarias, destilarias, refinarias de banha, serrarias, moinhos, engenhos de arroz e produção de azeite, salsichas, refrigerantes, sabão, arame, vassouras etc. A maioria desses produtos eram processados por pequenas agroindústrias, queijarias, moinhos e destilarias.

O sistema colonial contemporâneo foi marcado pela ampliação da produção de excedentes agrícolas (em especial de suínos, derivados de leite, produtos coloniais diversos etc.) e de uma maior inserção no mercado. No entanto, a limitação das superfícies agrícolas disponíveis e o aumento da população acarretaram uma crise no sistema de cultivo com tração animal leve e geraram um êxodo rural dos agricultores e de seus descendentes para novas regiões de colonização. Cabe salientar que esse período é fortemente marcado por uma importante diferenciação socioeconômica no âmbito da agricultura de cunho familiar, pois ocorre a formação e consolidação de um segmento de agricultores familiares capitalizados e fortemente tecnificados.

No Vale do Taquari, o complexo agroalimentar destaca-se pela produção de leite, frangos e suínos, cenário no qual as cooperativas agropecuárias têm se destacado pelo sistema de integração, 
constituindo mercados sólidos para os agricultores. As cooperativas agroindustriais caracterizam-se pela associação de agricultores, geralmente com base cultural comum, que se reúnem sob um arcabouço organizacional e institucional próprio, voltado especialmente para ganhos de escala e poder perante os clientes.

A simplificação dos sistemas de culturas, a especialização e intensificação produtiva levam à perda de autonomia das famílias, conferindo-lhes uma posição subordinada e cada vez mais vulnerável em relação ao mercado. No entanto, paralelo à produção para os mercados, as práticas de produção para o autoconsumo e agroindustrialização, herança cultural, continuaram presentes na cultura do território. Em momentos de crise do sistema hegemônico ou estímulo para a diversificação, através de políticas públicas de valorização dessas práticas, elas emergem como contra movimentos e constituem estratégias de desenvolvimento.

A agricultura familiar tem um papel fundamental para o desenvolvimento do território, a diversidade de saberes e práticas desenvolvidas pelas populações no uso dos recursos naturais. Isso deu origem a estratégias de desenvolvimento bastante heterogêneas, de grande potencial de geração de renda, uso da mão de obra, organização social e política.
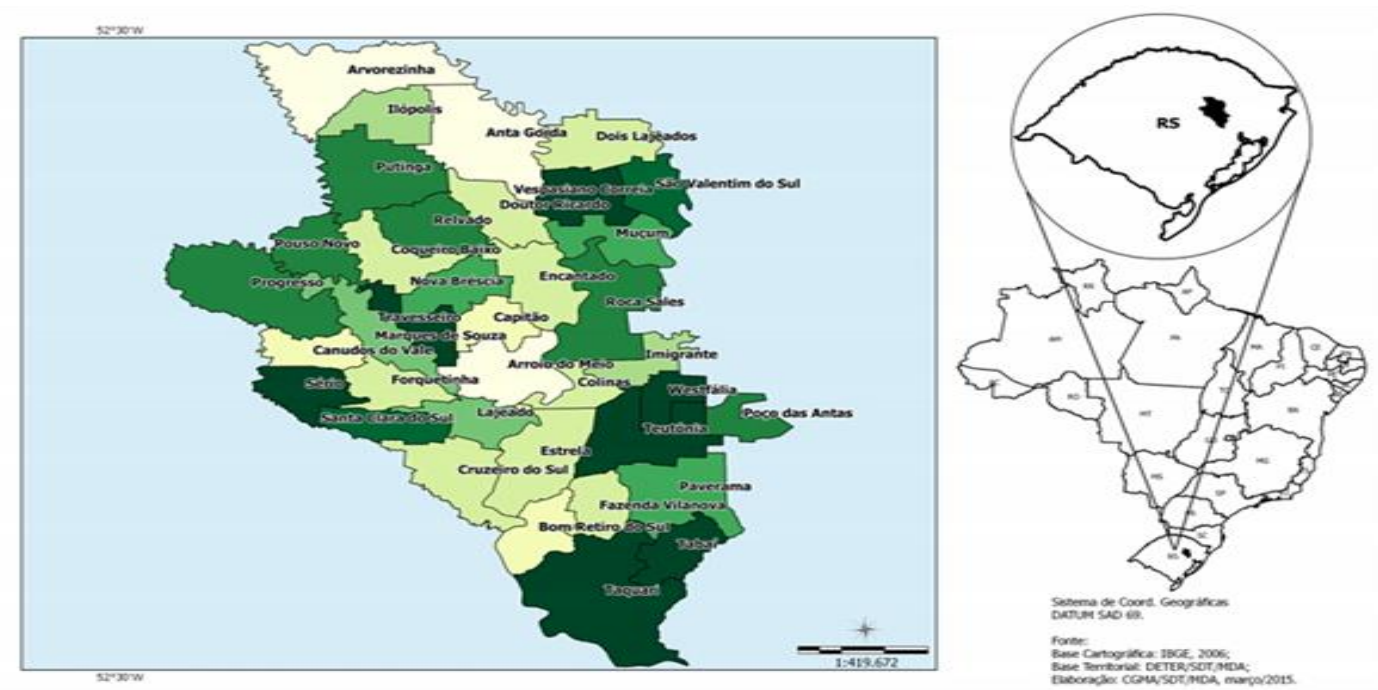

FIGURA 1 - MAPA DO VALE DO TAQUARI - RS FONTE: Kolchinski et al., 2017

O Vale do Taquari encontra-se na região central do estado do Rio Grande do Sul, distante cerca de $150 \mathrm{~km}$ de Porto Alegre. Tem 4.821,1 km² de área (1,71\% da área do estado) e 355.418 habitantes (3,07\% do estado - Censo demográfico 2010). Conforme Kolchinski et al., 2017 a população rural do Vale do Taquari, com 87.153 habitantes (2013) corresponde a 26,42\% da população do território que tem sua base econômica e social alicerçada na pequena produção rural, com 24.067 estabelecimentos da agricultura familiar, representando $93,9 \%$ do total de 
estabelecimentos, bem superior à média do estado, que corresponde a 14,9\%. Nesse contexto, 60.787 são enquadrados como agricultores familiares, demonstrando a sua importância para geração de renda.

A urbanização do território acentuou-se após 1990, quando a população urbana do Vale do Taquari cresceu 18,93\% em comparação aos dados dos Censos do IBGE de 2000 e 2010, sendo que do estado aumentou em $9,41 \%$. Os dados também revelam que o Vale do Taquari perdeu 11,10\% de sua população rural no mesmo período.

A economia local representa 3,2\% do total do Produto Interno Bruto (PIB) gaúcho. Em 2013, o município de Lajeado foi considerado o mais desenvolvido do $\mathrm{RS}$ e $13^{\circ}$ mais desenvolvido do país, segundo o Índice Firjan de Desenvolvimento Municipal (IFDM), atingindo 0,8813. A produção de alimentos constitui-se uma das principais atividades econômicas do território; destaca-se a heterogeneidade da agricultura familiar, que apesar do sistema agroalimentar hegemônico, organizado em torno das cadeias longas de produção de leite, suínos e frangos, possibilitou a manutenção de práticas como a produção para o autoconsumo, a agroecologia e a agroindustrialização.

\section{Arranjo Produtivo Local (APL) e a agroindustrialização do Vale do Taquari}

O desenvolvimento local voltou a ganhar relevância nos últimos anos, em especial a promoção de Arranjos Produtivos Locais (APLs). Estes se referem a uma forma de aglomeração produtiva de empresas produtoras de bens e serviços afins, que são favorecidas por políticas e ações dos poderes públicos e privados, instituições de pesquisa e centros de tecnologia, e destacam-se por sua capacidade de geração de empregos. O estado do Rio Grande do Sul foi pioneiro em criar políticas para Arranjos Produtivos Locais (APLs) quando, no início dos anos 2000, apoiou os sistemas locais de produção (SLPs). Desde então, continua apoiando os APLs, mas foi somente em 2011, ao ser aprovada a Lei n. ${ }^{\circ}$ 13.839, que instituiu a Política Estadual de Fomento à Economia da Cooperação, que foi criado o Programa Estadual de Fortalecimento das Cadeias e Arranjos Produtivos Locais e que começou a tomar a forma em que está estruturado atualmente.

O APL Agroindústria familiar Vale do Taquari está enquadrado no Programa Estadual de Fortalecimento das Cadeias e APLs desde agosto de 2013, contando inicialmente com 38 agroindústrias cadastradas. Esse número foi crescendo gradativamente e em dezembro de 2017 ocorreu a inclusão de mais 8 municípios, totalizando 20 municípios e 85 estabelecimentos. 
Entre os produtos agroindustrializados estão açúcar-mascavo, melado, rapadura, aguardente, carne e embutidos, banha e torresmo, conservas, doces e geleias, sucos, vinho, nozes, massas congeladas, bolachas, pães, cucas, aipim descascado e congelado, queijos e erva-mate.

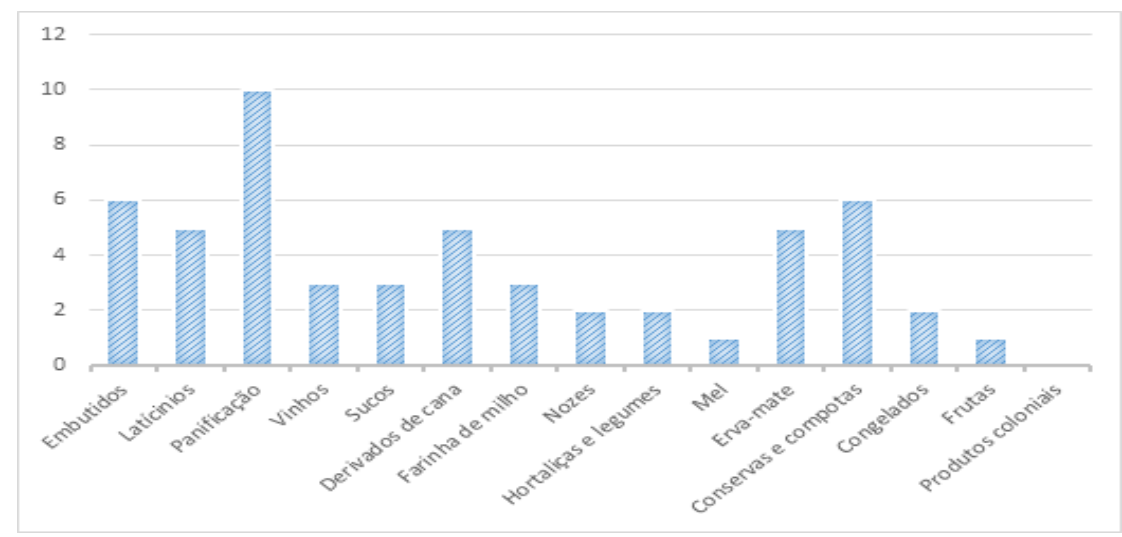

GRÁFICO 1 - DISTRIBUIÇÃO DAS AGROINDÚSTRIAS ASSOCIADAS AO APL AGROINDÚSTRIA POR TIPO DE PRODUÇÃO EM 2017

FONTE: Dos autores, adaptado de APL AGROINDÚSTRIA VALE DO TAQUARI (2017).

Grande parte das agroindústrias associadas ao APL já existia antes da política pública que instituiu o arranjo, porém, destaca-se a capacidade de fomentar o associativismo e a governança, que possibilitou cursos de formação como os de Boas Práticas de Fabricação (BPF) e gestão da propriedade, ofertados pelo Senar e Sebrae, além de inúmeras visitas técnicas a diversas regiões do país e uma viagem à Itália. Destaca-se grande participação feminina entre as agroindústrias participantes, não apenas no processo de produção, mas também na gestão e governança.

No norte do Vale do Taquari, colonizado por imigrantes italianos e alemães, as agroindústrias sempre fizeram parte da dinâmica social, constituindo uma alternativa de renda para famílias de agricultores, evidenciando a grande importância econômica. Nesse cenário, políticas públicas de apoio e incentivo, como os Arranjos Produtivos Locais e o acesso a crédito para aumentar a capacidade investimento dos agricultores podem potencializar o associativismo, a formação de novas redes sociotécnicas e novos mercados.

A valorização da produção agroindustrial, fruto de políticas públicas de incentivo, a partir dos anos 2000, estimulou a legalização dos estabelecimentos. O selo Sabor Gaúcho é uma marca que identifica os produtos com origem na agricultura familiar gaúcha que participam do Programa Estadual de Agroindústria Familiar (PEAF). Agroindústrias que estão com as questões fiscal, sanitária e ambiental em dia podem solicitar autorização para utilizarem o selo Sabor Gaúcho em seus produtos. 
Quanto à fiscalização e enquadramento, a maioria está legalizada através da inspeção da Vigilância Sanitária ou enquadrada no SIM (Sistema Municipal de Inspeção), que permite a comercialização apenas dentro do município, ou em casos excepcionais, em grandes feiras, como a Expointer, cuja participação está regulada por editais. Apesar do número expressivo de estabelecimentos, a maioria dos municípios ainda não possui o Susaf (Sistema Unificado Estadual de Sanidade Agroindustrial Familiar, Artesanal e de Pequeno Porte), regulamentado pelo Decreto Estadual $n^{\circ} 49340$, de 05 de julho de 2012, que permite aos estabelecimentos registrados nos Serviços de Inspeção Municipais o comércio em todo o território do estado do Rio Grande do Sul, o que só caberia àqueles registrados na Secretaria da Agricultura, Pecuária e Agronegócio (Seapa) por meio do Serviço Estadual de Inspeção (Cispoa).

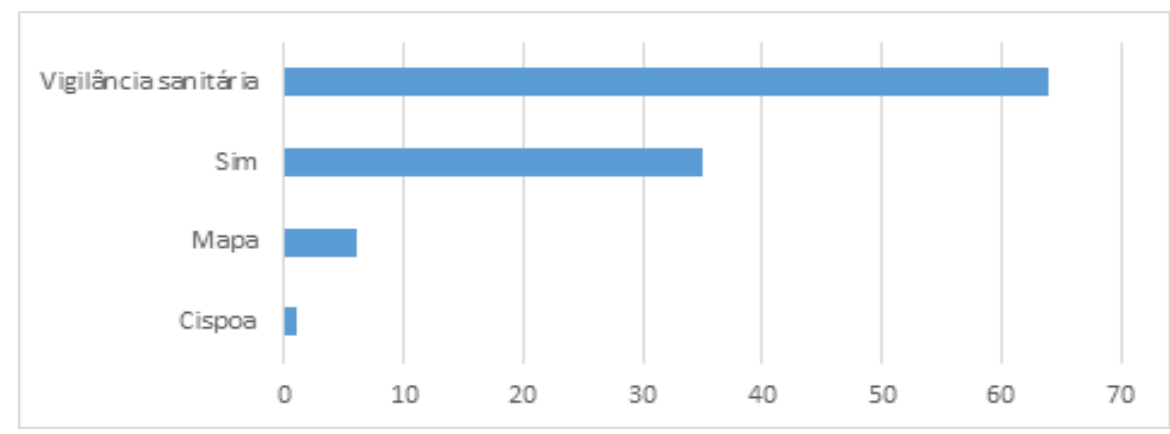

GRÁFICO 2 - TIPO DE INSPEÇÃO DAS AGROINDÚSTRIAS INTEGRANTES DO APL AGROINDÚSTRIA VALE DO TAQUARI

FONTE: Dos autores, adaptado de APL AGROINDÚSTRIA VALE DO TAQUARI (2017).

No momento, discute-se entre o grupo gestor do APL o desenvolvimento de um Selo de identificação geográfica, para os produtos das Agroindústrias do Vale do Taquari, cujo objetivo é dar maior visibilidade aos alimentos que são produzidos no território e suas particularidades. O grupo gestor e a Amturvales, entidade que promove o turismo, estudam integrar o trabalho das agroindústrias com os roteiros turísticos ligados ao ecoturismo através de um centro de atendimento ao turista e uma loja com todos os produtos das agroindústrias participantes.

Observa-se a necessidade de dar continuidade ao trabalho de fortalecimento da governança do APL, bem como buscar a ampliação com a adesão de mais agroindústrias. Para fortalecer o trabalho destacam-se as ações: contratação de equipe técnica, um gestor executivo e um auxiliar administrativo; realização de reuniões mensais com a Governança do APL; realização de visitas de mobilização e acompanhamento das agroindústrias e instituições; eventos técnicos de interesse do APL; articulação e apoio à participação das agroindústrias em feiras, como expositoras; criação de 
site do APL; integração com o turismo através da criação de rotas gastronômicas integradas a roteiros de ecoturismo.

O Arranjo Produtivo, instituído por meio de política pública, exerce papel de agência que fomenta o associativismo e a organização dos agricultores que estão redescobrindo práticas de produção de alimentos historicamente construídas, como um espaço de manobra e resistência à subordinação aos mercados hegemônicos. A estrutura de governança proporciona estímulos a novos circuitos de produção e comercialização, diversificando a agricultura familiar, gerando renda, incentivando a sucessão familiar.

\section{O turismo como estratégia de diversificação e criação de novos mercados}

A inserção do turismo no Vale do Taquari como atividade econômica é bastante recente e com a criação da Amturvales, em 1990, alguns importantes avanços ocorreram. No início dos anos 1990, novas práticas sociais surgem, além de roteiros gestados por prefeituras, como a Rota Germânica, em Teutônia, e Delícias da Colônia, roteiro que integra os municípios de Estrela, Colinas e Imigrante. Em 1995 é oficializada a criação da Amturvales, composta por entidades de iniciativa privada e poder público, tendo como objetivo planejar e coordenar ações de turismo no território.

Entre as ações desenvolvidas está a organização de materiais de divulgação com a Secretaria de Turismo do estado e elaboração de um planejamento estratégico para o setor pelo Conselho de Desenvolvimento do Vale do Taquari (Codevat). O objetivo desse planejamento foi criar um processo participativo que resultou na formulação do Plano turístico do Vale do Taquari e no Turisvale, comitê gestor do turismo no vale. Após os anos 2000, as ações passaram a ser focadas na valorização da diversidade de paisagens e culturas do vale, estimulando a criação de vários roteiros:

a) Caminho dos Moinhos - contempla os municípios de Anta Gorda, Arvorezinha, Ilópolis e Putinga. O passeio mostra ao turista admiráveis registros da imigração italiana, do começo do século passado, como os moinhos de farinha que resistiram ao tempo e continuam em atividade.

b) Caminhos da Forqueta - oferece visitação a igrejas, museu, apiário, alambique, café colonial, restaurante, horta orgânica, relógio de chás, compostagem orgânica, trilha e mirante.

c) Rota da erva-mate - a erva-mate inspirou a formação deste roteiro, que é constituído pela união de 10 municípios: Anta Gorda, Arvorezinha, Coqueiro Baixo, Doutor Ricardo, Encantado, Ilópolis, Itapuca, Nova Bréscia, Putinga e Relvado. No percurso de aproximadamente 80 quilômetros, o turista encontra um conjunto de atrativos turísticos acompanhado de belas paisagens naturais emolduradas entre vales e morros, aliado também à saborosa gastronomia italiana e à hospitalidade interiorana, característica de 
uma comunidade de colonização italiana, mas que também carrega fortemente a identidade do povo gaúcho.

d) Rota Germânica - conhecida por seus 15 pontos turísticos, 12 em Teutônia e três em Westfália, permite ao turista conhecer um pouco mais da cultura germânica por meio das tradições que ainda hoje são cultivadas, como a confecção do sapato de pau, símbolo dos dois municípios, além da culinária, arquitetura germânica e belas paisagens.

e) Rota Turística Trilhas e Memórias - está em formatação com o objetivo de integrar os municípios de Boqueirão do Leão, Canudos do Vale, Cruzeiro do Sul, Forquetinha, Marques de Souza, Progresso, Santa Clara do Sul e Sério. O turista conhece nessa região as marcas das colonizações alemã e italiana, paisagens deslumbrantes por entre os vales e os rios, aliadas à acolhida de um povo simples e hospitaleiro.

f) Roteiro Encantado - localizado no município de Encantado, o roteiro consiste num passeio por atrações turísticas, culturais, religiosas, artesanais e históricas de Encantado.

g) Roteiro Turístico Delícias da Colônia - oferece um tour por pontos turísticos de Estrela, Colinas e Imigrante. Nos passeios, os visitantes contemplam desde as pastagens aos casarios de época, passando por locais que exaltam a gastronomia típica e a hospitalidade interiorana.

h) Roteiro Turístico Taquari Açoriano - realiza um tour pela cidade de Taquari, município que no ano de 1760 recebeu os primeiros imigrantes provindos do arquipélago dos Açores e que iniciaram a colonização do Vale.

i) Tour por Lajeado - o roteiro consiste num passeio com ônibus aberto por Lajeado, maior cidade do Vale, para conhecer seus pontos turísticos, parques, margens do Rio Taquari e história.

Além desses roteiros, existe o turismo de eventos, que configura uma nova prática social, tornando-se muito comuns na região, como a Expovale (Lajeado), Suinofest (Encantado), Festa de Maio (Teutônia), Expofeira (Estrela) e festas de comemoração de aniversário de municípios e de cunho religioso. Com o trabalho desenvolvido, o número de turistas vem crescendo, como se pode observar no gráfico.

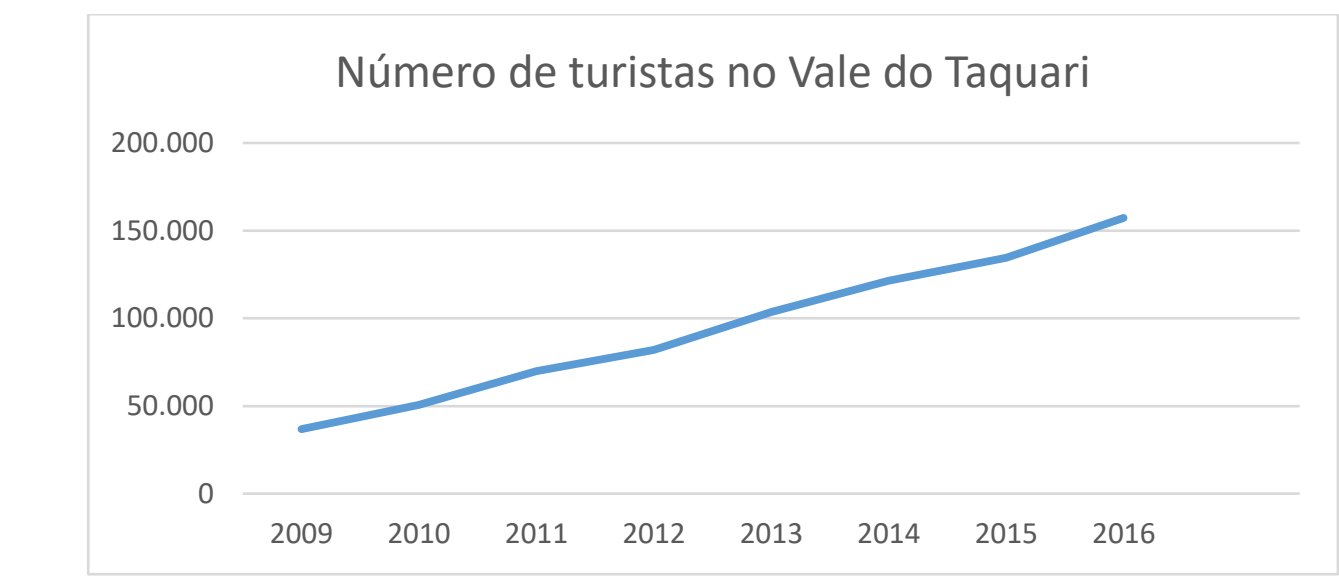

GRÁFICO 3 - NÚMERO DE TURISTAS QUE VISITARAM O VALE DO TAQUARI (2009-2016)

FONTE: Dos autores, adaptado de AMTURVALES (2017). 
O crescimento do número de turistas leva as instituições como o Sebrae e a Amturvales a apostarem na formação de novos roteiros e grupos. O ecoturismo, o turismo rural e o gastronômico são projetos em construção no território.

O turismo rural em propriedades de agricultores familiares traz novas oportunidades de agregação de valor e aumento da renda. A associação entre o turismo e o modo de vida das famílias rurais está demonstrando que essa é uma estratégia altamente promissora para o desenvolvimento local. Potencialidades que o meio rural sempre pôde oferecer, mas por falta de políticas públicas locais de incentivo, bem como pela carência de uma mentalidade empreendedora baseada no associativismo, agora estão sendo estimuladas e potencializadas pela expansão das áreas urbanas e a emergência de uma nova ruralidade.

\section{Considerações finais}

A agricultura familiar constitui a base do desenvolvimento econômico e social do Vale do Taquari. A diversidade cultural presente desde a ocupação do território e a heterogeneidade das práticas alimentares contribuíram para a construção do conhecimento local acerca dos sistemas de produção, agroindustrialização de alimentos e para a construção da estrutura social que tem no associativismo sua sustentação.

A preocupação com a segurança alimentar dos imigrantes que ocuparam o Vale fomentou a adoção de práticas como a produção para o autoconsumo, garantindo o acesso a uma variedade de alimentos de origem vegetal e animal. A comercialização dos excedentes foi dando origem a mercados, fortalecidos graças ao sistema cooperativista que alavancou o desenvolvimento. A modernização estimulou a mercantilização da agricultura, que através de práticas de poderes em escalas locais e mundiais resultou na consolidação de um mercado agroalimentar hegemônico, orientado pela escala, produtividade e distanciamento entre agricultores e consumidores.

A agroindústria familiar é uma estratégia de reprodução social e de desenvolvimento rural importante na agricultura familiar no Vale do Taquari, pois é responsável pela fixação das famílias no campo, pela diversificação de atividades produtivas e agregação de renda à produção, promovendo novos arranjos sociais e estruturas de governança horizontalizadas. As práticas de agroindustrialização sempre estiveram presentes na história do Vale, resistindo ao processo de modernização, com 215 estabelecimentos cadastrados na Secretaria Estadual de Desenvolvimento 
Rural. Políticas públicas de incentivo foram fundamentais para sua regularização e enquadramento às normas sanitárias e organização do sistema produtivo.

A construção e o acesso a novos mercados, a criação e o desenvolvimento de novos produtos e/ou processos produtivos, a formação e a consolidação de novas organizações locais superam a mera produção de mercadorias, desenvolvendo a autonomia dos agricultores familiares e possibilitando a sua reprodução social. A qualidade passa a ser fator chave nesse processo e cresce a necessidade de se (re)construir a relação de confiança ente produtores e consumidores, fazendo crescer a valorização dos alimentos produzidos localmente e a produção orgânica, agroecológica e artesanal das cadeias curtas, o que permite uma reconexão entre produtores e consumidores através de Sistemas Agroalimentares Localizados, Sial, fortemente enraizado no território.

A criação de novos arranjos que facilitem o acesso a alimentos saudáveis, como cestas de produtos, grupos de consumo e a integração entre as práticas agroecológicas e agroindustriais ampliam a oferta de alimentos para o consumidor e agregam valor para o agricultor. A integração entre as práticas de agroindustrialização com o turismo pode acelerar o processo de transição, relocalizando o sistema agroalimentar, criando novos mercados com a criação de roteiros que valorizem a gastronomia local, associada à paisagem, ao ecoturismo. A criação de selos de origem e identificação do território está em análise e pode contribuir para a valorização da produção local, agregando valor à produção. A importância da construção territorial, da inovação em produtos e serviços, em que a dimensão territorial constitui uma dimensão essencial de todo processo de inovação, fortemente ancorada em práticas sociais.

O crescimento no número de turistas e a proposição de novos roteiros, novas práticas sociais e a integração entre as práticas, através de novos arranjos materiais e sociais, integrando a paisagem, as práticas alimentares e a cultura do Vale do Taquari constituem um projeto de desenvolvimento rural. A aproximação entre o rural e o urbano confere maior autonomia aos agricultores, agregando valor à produção e atribuindo novas funcionalidades à propriedade, incorporando novos significados e práticas ao modo de vida dos agricultores familiares.

A heterogeneidade da agricultura familiar do território pode ser observada pela diversidade de produtos e processos de agroindustrialização, que colaboram para a agregação de valor e a relocalização do sistema agroalimentar, reconectando agricultores e consumidores. $\mathrm{O}$ resgate das práticas artesanais de produção de alimentos, adequando-as à legislação vigente, construindo novos padrões de qualidade, que atendam ao consumidor e possibilitem a autonomia dos agricultores diante dos mercados, constitui-se uma inovação social, uma estratégia para o desenvolvimento rural. 


\section{Referências}

AHLERT, L.; GEDOZ, S. T. Povoamento e desenvolvimento econômico na região do Vale do Taquari, Rio Grande do Sul - 1822 a 1930. Revista Estudo \& Debate, Lajeado, v. 8, n. 1, p. 49-91, 2001.

APL AGROINDÚSTRIA VALE DO TAQUARI. Disponível em: <http://www.aplvaledotaquari.com.br/agroindustrias/agroindustrias-participantes. Acesso em: 25 jun. 2017.

ASSOCIAÇÃO DOS MUNICÍPIOS DE TURISMO DA REGIÃO DOS VALES - AMTURVALES. Disponível em: <http://www.amturvales.com.br/roteiros>. Acesso em: 30 nov. 2017.

CIRAD. Systèmes agroalimentaires localisés: organisations, innovations et développement local. Montpellier: Cirad, 1996.

FONTE, M. Knowledge, food and place: a way of producing, a way of knowing. Sociologia Ruralis, v. 48, n. 3, p. 200-222, 2008.

GOODMAN, D. The quality "turn" and alternative food practices: reflections and agenda. Journal of Rural Studies, v. 19, n. 1, p. 1-7, 2003.

GOODMAN, D. DUPUIS, M. E., GOODMAN, M. K. Alternative food networks: knowledge, practice, and politics. London; New York: Routlege, 2012.

ILBERY, B. et al. Product, process and place an examination of food marketing and labelling schemes in Europe and North America. European Urban and Regional Studies, v. 12, n. 2, p. 116-132, 2005.

KOLCHINSKI, E., ZANETTI, C., BIONDO, E. and OLIVEIRA, L. Plano territorial de desenvolvimento rural sustentável do Vale do Taquari. 1 ed. Encantado: UERGS, 50 p, 2017.

LONG, N. Development sociology: actor perspectives. London: Routledge, 2001.

MALUF, R. Mercados agroalimentares e a agricultura familiar no Brasil: agregação de valor, cadeias integradas e circuitos regionais. Ensaios FEE, Porto Alegre, v. 25, n. 1, p. 299-322, abr. 2004.

MENASCHE, R. Saberes e sabores da colônia: alimentação e cultura como abordagem para o estudo do rural. Porto Alegre: Editora da UFRGS, 2015.

MIOR, L. C. Agricultores familiares, agroindústrias e redes de desenvolvimento rural. Chapecó: Argos, 2005.

MUCHNIK, J. Les systèmes agroalimentaires localisés: intérêt, approche, interrogations. In: Colloque Syal. Montpellier, 2002.

OBSERVATÓRIO BRASILEIRO DE ARRANJOS PRODUTIVOS LOCAIS. Disponível em: $<$ http://portalapl.ibict.br>. Acesso em: jun. 2017.

PECQUEUR, B. Qualité et développement territorial: 1'hypothèse du panier de biens et de services territorialisés. Economie Rurale, 261, 2001. 
PECQUEUR, Bernard. A guinada territorial da economia global. Política e Sociedade: Revista de

Sociologia Política, PPSP UFSC, vol 8, n 14, 2009. Disponível em: http://www.periodicos.ufsc.br/index.php/politica/article/view/11615/10955 Acesso em: 05 jun. 2016.

PORTAL VALE DO TAQUARI. Caminhos da Forqueta: roteiro turístico torna-se realidade em Arroio do Meio. Disponível em: <https://bit.ly/2selvyc>. Acesso em: out. 2017.

\section{RELATÓRIO DECENAL ARRANJOS PRODUTIVOS LOCAIS. APL Agroindústria Familiar}

Vale do Taquari. Disponível em:

<http://www.sdect.rs.gov.br/upload/arquivos/carga20170526/04092652-1418296733-relat-c3-

b3rio-20decenal-20apl-20agroind-c3-bastria-20familiar-20do-20vale-20do-20taquari.pdf $>$. Acesso em: 12 jan. 2018.

RIO GRANDE DO SUL, Lei 13839/2011; Institui a Política Estadual de Fomento à Economia da Cooperação Disponível em:

http://www.al.rs.gov.br/FileRepository/repLegisComp/Lei\%20n\%C2\%BA\%2013.839.pdf. Acesso em 10 de março de 2018.

RIO GRANDE DO SUL, Instrução Normativa N 02/2013; Aprova os Requisitos para Adesão dos Municípios ao Sistema Unificado Estadual de Sanidade Agroindustrial Familiar, Artesanal e de Pequeno Porte-SUSAF-RS. 2013.

RIO GRANDE DO SUL, Decreto No 49340 DE 05/07/2012; dispõe sobre o Sistema Unificado Estadual de Sanidade Agroindustrial Familiar, Artesanal e de Pequeno Porte - SUSAF-RS. Disponível em: https://www.legisweb.com.br/legislacao/?id=243083. Acesso em 10 de março de 2018.

TREGEAR, A. Progressing knowledge in alternative and local food networks: critical reflections and a research agenda. Journal of Rural Studies, v. 27, n. 4, p. 419-430, 2011.

WILKINSON, J. A pequena produção e sua relação com os sistemas de distribuição. In: Seminario Políticas de Seguridad Alimentaria y Nutrición em América Latina (palestra). Campinas: Unicamp, 2003.

Artigo recebido em 19/08/2018. Aceito para publicação em 08/11/2018. 